African Journal of Educational Studies in Mathematics and Sciences Vol. 15, 2019

\title{
Van Hiele Geometric Thinking Levels of Junior High School Students of Atebubu Municipality in Ghana
}

\author{
B. Amidu and J. Nyarko
}

\begin{abstract}
This study was to measure the Van Hiele's levels of geometric thinking attained by Ghanaian Junior High School Form 3 (JHS 3) students before writing the BECE. A quantitative research approach was employed in the study and sample of 105 students randomly selected from the four schools. The results showed that 22 students $(20.95 \%)$ of the students could not attain any VHG level at all, that means they were in level 0.65 students $(61.91 \%)$ of the students attained Van Hiele's level 1, $17(16.19 \%)$ reached level 2 , and only $1(0.95 \%)$ reached level 3 . An independent t-test yielded no statistically significant difference between public and private school students in their geometric thinking levels $\mathrm{t}(103)=0.926, \mathrm{p}>0.05$. The findings indicated that most of the Ghanaian JHS graduates do not attain satisfactory levels of VHGT. Recommendations are made for improving the teaching of geometry.
\end{abstract}

Keywords: $\quad$ geometry, geometric thinking, van Hiele's levels, visualization, cognitive development

\section{Introduction}

There has being a growing interest in the teaching and learning of geometry since the mid of 1980s (e.g., Crowley, 1987; Gutierrez, Jaime, \& Fortuny, 1991; Clements \& Battista, 1990; Mason, 1997; Lappan, Fey, Fitzgerald, Friel, \& Phillips, 1996; Baffoe \& Mereku, 2010; Armah, Cofie \& Okpoti, 2017; Asemani, Asiedu-Addo \& Oppong 2017). Ghana participated in Trends in International Mathematics and Science Study (TIMSS) in order to find out how the performance of her eighth graders (JSS2) in science and mathematics compared with those of other countries. According to TIMSS 2011 report, Ghanaian students' performance in mathematics also indicated that, algebra and geometry were the weak content areas (Mullis, Martin, Foy \& Aron, 2011). In view of this abysmal performance of Ghanaian students, mathematics educators have put up maximum efforts aimed at identifying the major problems associated with the teaching and learning of mathematics in the nation's schools.

According to Atebe (2008) as cited in Asemani, Asiedu-Addo \& Oppong (2017), geometry provides a more complete appreciation of the world we live in (For example, geometry appears naturally in the structure of the solar system, in geological formation of plants and flowers, and even in animals. It is also a major part of our synthetic world such as art, architecture, cars, machines, and virtually everything humans create. There has been a great deal of concern about the level of students understanding of geometry in Ghanaian schools.

\footnotetext{
${ }^{1}$ Amidu Bashiru is a Mathematics Educator and researcher at Attebubu College of Education, Ghana. Email: <bashidow@yahoo.com>

${ }^{2}$ Josephine Nyarko is a Mathematics Educator at Mampong College of Education, Ghana.
} 
Van Hiele Geometric Thinking Levels of Junior High School Students of Atebubu Municipality in Ghana

B. Amidu and J. Nyarko

The study of geometry contributes to helping students develop the skills of visualization, critical thinking, intuition, perspective, problem-solving, conjecturing, deductive reasoning, logical argument and proof. Geometric representations can also be used to help students make sense of other areas of Mathematics: fractions and multiplication in arithmetic, the relationships between the graphs of functions (of both two and three variables), and graphical representations of data in statistics (NCTM, 2009).

There has been concerns raised about the levels of students' geometric thinking in Ghanaian schools, especially at the basic school level (Anamuah-Mensah \& Mereku (2005); AnamuahMensah, Mereku \& Asabere-Ameyaw, (2008); Baffoe \& Mereku, (2010). In Addition, the West African Examination Council (WAEC) Chief Examiners annual reports for the SSSCE \& WASSCE from 2003 to 2006 observed that candidates were weak in Geometry of circles and 3dimensional problems. According to their reports, most candidates avoided questions on 3dimensional problems, where they attempted geometry questions; only few of the candidates showed a clear understanding of the problem in their working.

Students' mathematical competencies have been closely linked to their levels of geometric understanding (Van Hiele, 1986; French, 2004). The van Hiele theory has been applied to many curricula to improve geometry classroom instruction in many developed nations but in Ghana, the literature appears to suggest that there has been little investigation involving the van Hiele theory. Thus, very little studies have applied the van Hiele theory to determine the level of geometric conceptualization of Ghanaian basic school and also to improve geometry instruction. Meanwhile, there is evidence that many students in Ghana encounter severe difficulties with school geometry (Baffoe, \& Mereku, (2010). Thus, this study was designed to fill this void in the literature on teaching geometry.

The purpose of this study was to find out the stages of the Van Hiele levels of understanding of Junior High School students in the study of geometry before writing the Basic Education Certificate Examination. In pursuance of this purpose, the following question was formulated to guide the study: -

1. Which stages of Van Hiele levels of understanding do Ghanaian students reach in the study of geometry before writing their BECE Examination?

2. To what extent is the performance of the Public schools differ from the Private schools in terms of Van Hieles levels of understanding.

\section{Theoretical framework}

The van Hiele model of geometric thought emerged from the doctoral works of Dina van HieleGeldof (1984a) and Pierre van Hiele (1984b), which were completed simultaneously at the University can be used to guide instruction as well as assess student abilities. What has become known as the van Hiele level theory was developed by Dina van Hiele-Geldof and her husband Pierre Marie van Hiele inseparate doctoral dissertations at the University of Utrecht in 1957.Dina died shortly after her dissertation was completed; Pierre has thus been the one to explicate the theory. In the years 1958-59, he wrote three papers (two in English, one in Dutch but translated into French) that received little attention in the West, but were applied1n curriculum development by the Soviet academician Pyshkalo (1968). Freudenthal, the van Hieles' mento .,, publicized the theory in his well-known book Mathematics as an Educational Task (1973). Through Freudenthal and the Soviets, the work of the van Hieles came to the attention of Wirszup, who was the first to 
speak about the van Hiele theory on this side of the Atlantic (1974) and later published his speech.(1976).

The van Hiele theory originally consists of five sequential and hierarchical discrete Levels of geometric thought namely: Recognition, Analysis, Order (Informal Deduction), Deduction, and Rigor, Usiskin, Z. (1982). There are two different numbering schemes that are commonly used to describe the van Hiele Levels: Level 0 through to 4, and Level 1 through to 5. Originally the van Hieles numbering scheme used Level 0 through to 4, however, Americans [Mason, (1998); Usiskin, (1982) and van Hiele's ((1986; 1999); more recent writings make use of the Level 1 through to 5 numbering schemes instead. This according to Mason (1998) allows for a sixth Level, Pre-recognition Level (i.e.

Level for learners who have not yet achieved even the basic Level 1) to be called Level 0 . This study used the Level 1 to 5 numbering scheme to allow utilization of Level 0. The van Hiele Levels can be described as follows:

Level 1: Recognition (or visual level) At this Level learner use visual perception and nonverbal thinking. They recognize figures by appearance alone "and compare the figures with their prototypes or everyday things ("it looks like a door"), categorize them ("it is / it is not a..."). They use simple language Vojkuvkova, (2012)". Learners at this Level do not identify the properties of geometric figures Van Hiele, (1999).

Level 2: Analysis (or descriptive level) At this Level, "figures are the bearers of their properties. A figure is no longer judged because it looks like one but rather because it has certain properties Van Hiele, (1999).”. Learners start analyzing and naming properties of geometric figures but they do not understand the interrelationship between different types of figures, and they also cannot fully understand or appreciate the uses of definitions at this level Mason, (1998).

Level 3: Order (or informal deduction level) Learners at this Level are able to see the interrelationship between different types of figures. They can create meaningful definitions and give informal arguments to justify their reasoning at this Level. Logical implications and class inclusions, such as squares being a type of rectangle, are understood Halat, E. (2008); Mason, (1998).

Level 4: Deduction: At this Level learners can give deductive geometric proofs. They understand the role of definitions, theorems, axioms and proofs. Learners at this Level can supply reasons for statements in formal proofs Halat, (2008); Vojkuvkova, (2012).

Level 5: Rigor Learners at this Level "understand the formal aspects of deduction, such as establishing and comparing mathematical systems Mason, (1998)". Here, learners learn that geometry needs to be understood in the abstract; see the "construction" of geometric systems. Learners at this level should understand that other geometries exist and that what is important is the structure of axioms, postulates, and theorems Crowley, (1987).

\section{Methodology}

\section{Research design and sample}

The descriptive research design was employed to investigate the Junior High School Students geometrical reasoning level and achievement scores using VHGT in private and Junior High School in Atebubu. The population was made up of all Junior high school preparing to write their BECE in 2018/ 2019 academic year. The convenience sampling method was used to select from 4 
Van Hiele Geometric Thinking Levels of Junior High School Students of Atebubu Municipality in Ghana

B. Amidu and J. Nyarko

schools (two private and two public) 114 final year students of Junior High school students in the Atebubu Municipality the sample.

\section{Instruments}

The VHGT which was developed by Usiskin (1982) under the Cognitive Development an achievement Secondary School Geometry (CDASSG) special programme was the main instrument for the research. The first 15 of the 25 multiple choice questions was administered to the 2018/2019 Junior High School pupils to measure their Geometric Thinking level. The duration for the test was 25 minutes. The VHGT is organized in a chronological order into five (5) subgroups such that it starts from lower thinking level to a higher thinking level. Each group of five covers a Van Hieles geometrical thinking level. The VHGT has been used by many researchers notably ( Usiskan, 1982; Hofferr, 1983; Mayberry, 1983; Fuys et al 1988; Abdullah and Zakaria, 2013; Halat, 2008; Armah et al, 2017; Asemani, 2017; Anas, 2018) to assess students geometrical thinking levels.

The VHGT has been used by many researchers and the content has been validated by them in the context in which they are been used. Two teachers of the Junior High school were tasked to go through the test items and they concluded that it met the standards of the content been taught in terms of geometry in the Junior High School level. 20 pupils from outside the selected schools were also given the test items to solve as a pilot. Kuder-Richardson formula 20 was used to determine the reliability coefficient of the instruments. A reliable coefficient of 0.72 was realized from the pilot analysis which indicate a high degree of reliability of the instrument.

Table 1: Nature of the VHGT test items.

\begin{tabular}{lll}
\hline Questions & Levels & Features \\
\hline $1-5$ & 1 & $\begin{array}{l}\text { It is about visual form. It aims to determine whether the students recognize the } \\
\text { shape by looking at the shape of the figure }\end{array}$ \\
$6-10$ & 2 & $\begin{array}{l}\text { It is concerned with the Characteristics of the forms and on the one hand it aims } \\
\text { to show that the students do not know the forms and on the other hand they do } \\
\text { not know the Characteristics of the forms. }\end{array}$ \\
& 3 & $\begin{array}{l}\text { It determines whether students can recognize the relationships between forms. } \\
\text { They identify students who respond correctly to questions in this group and have } \\
\text { proven that they have knowledge of axioms }\end{array}$ \\
\hline
\end{tabular}

Source: grading systems and Level Assignment

The 15 items multiple choice test was allocated 1 mark each a correct answer. So the expected maximum mark was 15 while a minimum mark expected was 0 . The researcher applied the ' 3 out of the 5' correct success criterion for the level assignment recommended by Usiskin (1982). A student is said to have mastered a given VHGT level if he/she correctly answered at least ' 3 out of the 5' items in any of the 5 subgroups. The PSTs were assigned a weighted sum as follows as proposed by Usiskin (1982): 1. 1 mark for attaining the standard on items 1-5 (Level 1, Recognition) 2. 2 marks for attaining the standard on items 6-10 (Level 2, Analysis) 3.4 marks for attaining the standard on items 11-15 (Level 3, Ordering) 4.8 marks for attaining the standard on items 16-20 (Level 4, Deduction) 5. 16 marks for attaining the standard on items 21-25 (Level 5, Rigor) This study adopted the Modified Case because it fits more students consistently than the classical Van Hiele level Usiskin (1982). Usiskin (1982) emphasized that in assigning levels in the 
Modified Case requires that a student's responses must satisfy property 1 of the levels that is students at level $n$ satisfy the criterion not only at that level but also at all preceding levels. Usiskin reiterated a student who satisfies the criterion at levels 1,2 and 5 would be assigned the Modified Van Hiele Level 2. Also, student who satisfies the criterion for only level 3 only would not be assigned modified Van Hiele level.

\section{Results}

The purpose of this study is to use VHGT to access and classifies students in Atebubu Municipality in Atebubu. The results were organized in SPSS and the table below shows the description of the total scores.

Table 2: $\quad$ Descriptive statistics on the total score of the JHS three students

\begin{tabular}{cccccc}
\hline & $\mathrm{N}$ & Minimum & Maximum & Mean & Std. Deviation \\
\hline Scores & 105 & 0 & 11 & 5.97 & 1.988 \\
\hline
\end{tabular}

From Table 2, the minimum mark is 0 whiles the maximum mark is 11 . The mean and the standard deviation of the students score are 5.98 and 1.988 respectively.

Table 3: $\quad$ Total scores obtained by the PSTs in VHGT by cumulative frequency.

\begin{tabular}{ccccc}
\hline Scores & $\begin{array}{c}\text { Number of students } \\
(\mathrm{N})\end{array}$ & $\begin{array}{c}\text { Percentage } \\
(\%)\end{array}$ & $\begin{array}{c}\text { Cumulative } \\
(\mathrm{CM})\end{array}$ & $\begin{array}{c}\text { Cumulative } \\
\%\end{array}$ \\
\hline 0 & 1 & .95 & 1 & 0.95 \\
1 & 1 & 0.95 & 2 & 1.9 \\
2 & 3 & 2.86 & 5 & 4.76 \\
3 & 7 & 6.67 & 12 & 11.43 \\
4 & 12 & 11.43 & 24 & 22.86 \\
5 & 17 & 16.19 & 41 & 39.05 \\
6 & 14 & 13.33 & 55 & 52.38 \\
7 & 29 & 27.62 & 84 & 79.00 \\
8 & 12 & 11.43 & 96 & 91.43 \\
9 & 8 & 7.62 & 104 & 99.05 \\
10 & 0 & 0 & 104 & 99.05 \\
11 & 1 & 0.95 & 105 & 100 \\
Total & 105 & 100.0 & & \\
\hline
\end{tabular}

From Table 3. It is realized that 84 out of 105 which represent $79 \%$ of the total number of JHS students who took part in the VHGT. Also, $12(11.43 \%)$ of the students obtained exactly half the total mark. Also, 9 JHS representing $8.57 \%$ of the total number performed above the half mark of 8. It was amazing to see that the maximum mark scored in the test was 11 out of 15 , which was obtained by only one JHS student. A close look at the performance of students shows that, general performance of both the private school and the public schools was below the expected performance of the Junior High School Students which is level 3. 
Van Hiele Geometric Thinking Levels of Junior High School Students of Atebubu Municipality in Ghana

B. Amidu and J. Nyarko

Table 4: $\quad$ JHS students subtest 1 performance on each item in the VHGT level 1

\begin{tabular}{rrrrrrr}
\hline & $\mathrm{A}$ & $\mathrm{B}$ & \multicolumn{1}{c}{$\mathrm{C}$} & \multicolumn{1}{c}{$\mathrm{D}$} & \multicolumn{1}{c}{$\mathrm{E}$} & \multicolumn{1}{c}{ Blank } \\
Item & \multicolumn{1}{c}{$\mathrm{N}(\%)^{1}$} & \multicolumn{1}{c}{$\mathrm{N}(\%)$} & \multicolumn{1}{c}{$\mathrm{N}(\%)$} & \multicolumn{1}{c}{$\mathrm{N}(\%)$} & \multicolumn{1}{c}{$\mathrm{N}(\%)$} & \multicolumn{1}{c}{$\mathrm{N}(\%)$} \\
\hline 1. & $2(1.9)$ & $95(90.48)$ & $2(1.9)$ & $4(3.81)$ & $2(1.9)$ & $0(0)$ \\
2. & $2(1.9)$ & $1(0.95)$ & $17(16.2)$ & $82(78.1)$ & $3(2.86)$ & $0(0)$ \\
3. & $28(26.67)$ & $1(0.95)$ & $70(66.67)$ & $2(1.9)$ & $4(3.81)$ & $0(0)$ \\
4. & $13(12.38)$ & $70(66.67)$ & $8(7.62)$ & $5(4.76)$ & $5(4.76)$ & $4(3.81)$ \\
5. & $15(14.29)$ & $18(17.14)$ & $41(39.05)$ & $23(21.9)$ & $4(3.81)$ & $4(3.81)$ \\
\hline
\end{tabular}

${ }^{1}$ Percentage in parenthesis

In level 1 of the VHGT, the performance of the JHS students was above average. In questions 1 , 2,3 , and 4 , their performance was above $50 \%, 90.48 \%, 78.10 \%, 66.67 \%$ and $66.67 \%$ respectively. while question 5 is 23 thus, $21.90 \%$. The question five is given below:

Which of these are parallelograms?

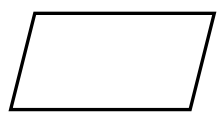

$\mathrm{J}$

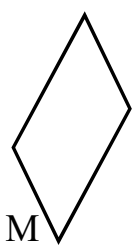

A. J only

B. L only

C. J and M only

D. All are parallelograms.

E. None of these are parallelograms

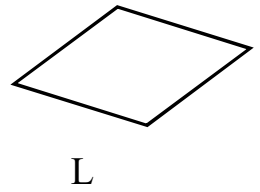

$\mathrm{L}$

The students were not able to answer this question correctly because they did not know that all quadrilaterals except trapezoid are parallelograms. Majority of the students rather chose $\mathrm{J}$ and $\mathrm{M}$ only which may be due to the misconception that parallelograms are in the form of rectangles and not squares.

Table 5: JHS students subtest 2 performance on each item in the VHGT level 2

\begin{tabular}{ccccrrr}
\hline & $\mathrm{A}$ & $\mathrm{B}$ & $\mathrm{C}$ & \multicolumn{1}{c}{$\mathrm{D}$} & \multicolumn{1}{c}{$\mathrm{E}$} & \multicolumn{1}{c}{ Blank } \\
Item & \multicolumn{1}{c}{$\mathrm{N}(\%)^{1}$} & \multicolumn{1}{c}{$\mathrm{N}(\%)$} & \multicolumn{1}{c}{$\mathrm{N}(\%)$} & \multicolumn{1}{c}{$\mathrm{N}(\%)$} & \multicolumn{1}{c}{$\mathrm{N}(\%)$} & \multicolumn{1}{c}{$\mathrm{N}(\%)$} \\
\hline 6. & $12(11.43)$ & $9(8.57)$ & $66(62.86)$ & $15(14.29)$ & $2(1.9)$ & $1(0.95)$ \\
7. & $22(20.95)$ & $6(5.71)$ & $16(15.24)$ & $17(16.19)$ & $44(41.9)$ & $1(0.95)$ \\
8. & $31(29.52)$ & $17(16.19)$ & $15(14.29)$ & $23(21.9)$ & $19(18.1)$ & $0(0)$ \\
9. & $13(12.38)$ & $20(19.05)$ & $63(60)$ & $5(4.76)$ & $4(3.81)$ & $0(0)$ \\
10. & $21(20)$ & $20(19.05)$ & $24(22.86)$ & $24(22.86)$ & $13(12.38)$ & $3(2.86)$ \\
\hline
\end{tabular}

${ }^{1}$ Percentage in parenthesis

The performance of the students in the second level except question 9 was not encouraging. Out of the number, only 9 students which is $8.57 \%$ of the students chose the answer B which is the 
correct answer. 44 students which is $41.90 \%$ scored correct in question 7.31 that is $29.52 \%$. 63 that is $60 \%$ in question 9 and 24 that is $22.86 \%$ in question 10 . For question 6 :

$\mathrm{PQRS}$ is a square.

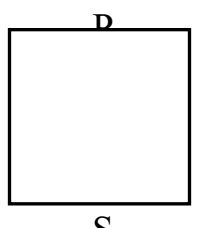

Q

$\mathrm{R}$

Which relationship is true in all squares?
A. PR and RS have the same length.
B. QS and PR are perpendicular.
C. PS and QR are perpendicular.
D. PS and QS have the same length.
E. Angle $\mathrm{Q}$ is larger than angle $\mathrm{R}$.

Students do not know the characteristics of the square. They did not also understand the meaning of perpendicular since $62.86 \%$ chose $\mathrm{C}$ which states that $\mathrm{PS}$ and $\mathrm{QR}$ are perpendicular.

7. In the rectangle GHJK, GJ and $\mathrm{HK}$ are the diagonals.

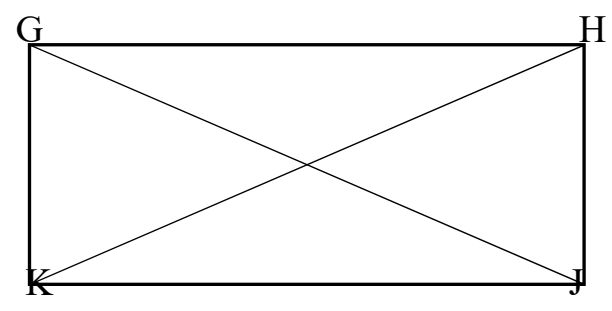

Which of (A)-(D) is not true in every rectangle?
A. There are four right angles.
B. There are four sides.
C. The diagonals have the same length.
D. The opposite sides have the same length.
E. All of (A)-(D) are true in every rectangle.

In question 7 above, was poorly answered only $41.9 \%$ of the students understood that all the above options are rectangle; $29.52 \%$ answered correctly the question 8 and $22.86 \%$ answered correctly the question 10, this may also be due to the fact that the students did not know the properties of a rhombus. 
Van Hiele Geometric Thinking Levels of Junior High School Students of Atebubu Municipality in Ghana

B. Amidu and J. Nyarko

Table 6: $\quad$ JHS 3 subset 3 performance on each item in the VHGT level 3

\begin{tabular}{rrrrrrr}
\hline & \multicolumn{1}{c}{$\mathrm{A}$} & $\mathrm{B}$ & $\mathrm{C}$ & \multicolumn{1}{c}{$\mathrm{D}$} & \multicolumn{1}{c}{$\mathrm{E}$} & \multicolumn{1}{c}{ Blank } \\
\multicolumn{1}{l}{ Item } & \multicolumn{1}{c}{$\mathrm{N}(\%)^{1}$} & \multicolumn{1}{c}{$\mathrm{N}(\%)$} & $\mathrm{N}(\%)$ & \multicolumn{1}{c}{$\mathrm{N}(\%)$} & \multicolumn{1}{c}{$\mathrm{N}(\%)$} & \multicolumn{1}{c}{$\mathrm{N}(\%)$} \\
\hline 11. & $\mathrm{~N}(\%)$ & $\mathrm{N}(\%)$ & $\mathrm{N}(\%)$ & $\mathrm{N}(\%)$ & $\mathrm{N}(\%)$ & $\mathrm{N}(\%)$ \\
12. & $21(20)$ & $19(18.1)$ & $24(22.86)$ & $4(3.81)$ & $10(9.52)$ & $37(35.24)$ \\
13. & $12(11.43)$ & $31(29.52)$ & $12(11.43)$ & $9(8.57)$ & $22(20.95)$ & $29(27.62)$ \\
14. & $9(8.57)$ & $8(7.62)$ & $19(18.1)$ & $3(2.86)$ & $57(54.29)$ & $9(8.57)$ \\
15. & $15(14.29)$ & $10(9.52)$ & $32(30.48)$ & $22(20.95)$ & $24(22.86)$ & $2(1.9)$ \\
\hline
\end{tabular}

${ }^{1}$ Percentage in parenthesis

The third level of the VHGT was questions in relationship between different shapes. It determines whether students can recognize the relationships between forms. They identify students who respond correctly to questions in this group and have proven that they have knowledge of axioms however students' performance at this level was poor. In all the questions that is from 11 to 15 , the performance was, $24,31,9,15$ and 28 which were $22.86 \%, 29.52 \%, 8.57,14.29 \%$ and $26.67 \%$ respectively. It could be said in general that student's knowledge on the concepts of the properties of similar shapes triangles and various quadrilaterals was very low as reflected in their performances.

Table 7: $\quad$ JHS 3 students' performance on VHGT level attainment.

\begin{tabular}{lcccc}
\hline Level & Level 0 & $\begin{array}{c}\text { Visualization } \\
\text { level 1 }\end{array}$ & $\begin{array}{c}\text { Analysis } \\
\text { Level 2 }\end{array}$ & $\begin{array}{c}\text { Order } \\
\text { Level 3 }\end{array}$ \\
\hline No & 22 & 65 & 17 & 1 \\
percentage & $20.95 \%$ & $61.91 \%$ & $16.19 \%$ & $0.95 \%$ \\
\hline
\end{tabular}

Table 7 shows the overall attainment level reached by the JHS 3 students. The table shows that 22 (20.95\%) of students attained No level, 65(61.91\%) attained level 1, 17 (16.19) attained level 2 and only $1(0.95 \%)$ attained level 3 which should have been the level for all the students in JHS 3 .

Figure 1 show the percentages of students from private and public schools reaching the three levels examined.

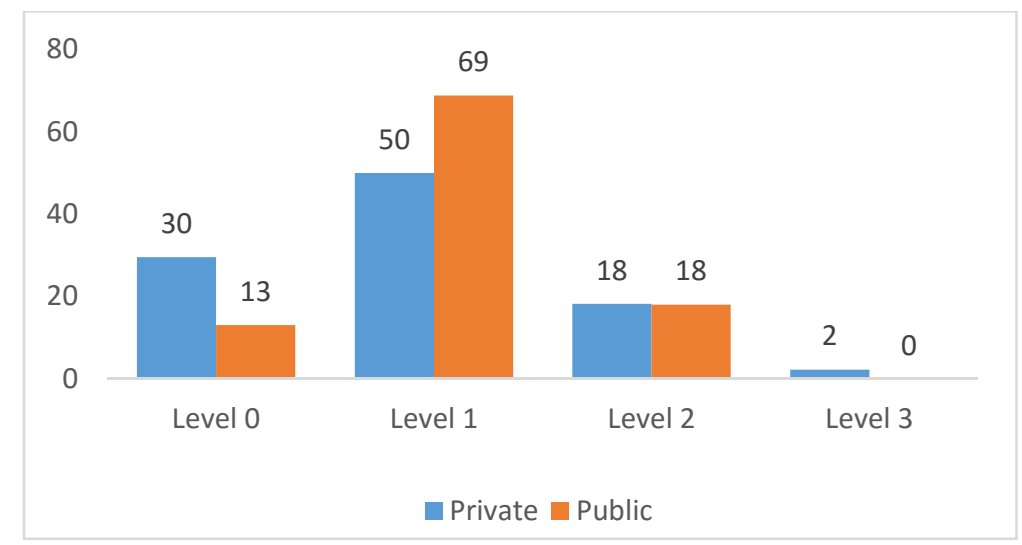

Figure 1 Percentages of students from private and public schools reaching the three van Hiele levels 
The figure shows that only $2 \%$ of private school students reached level 3 while none of the public school students reached this level. Majority of the students (50\% public and $69 \%$ private) are in Level 1 (i.e. Visualization level).

The marks obtained by the students in private and public schools were further explored to see whether the differences observed in the means (private $\mathrm{M}=6.25, \mathrm{SD}=2.324$; public $\mathrm{M}=5.89$, $\mathrm{SD}=1.714$ ) were statistically significant. The results of an independent t-test carried to test the null hypothesis that "there is no significant difference between the public schools and the private school in their geometric thinking levels" are presented in Table 8.

Table 8: $\quad$ JHS 3 students' performance on VHGT level attainment.

\begin{tabular}{cccccccc}
\hline School type & $\mathrm{N}$ & Mean & Std. Deviation & $\mathrm{F}$ & $\mathrm{t}$ & $\mathrm{df}$ & Sig. (2-tailed) \\
\hline Private & 44 & 6.25 & 2.324 & 3.491 & 0.926 & 103 & 0.357 \\
Public & 61 & 5.89 & 1.714 & & & & \\
\hline
\end{tabular}

The statistics from Table 8 indicate that there is no statistically significant difference between the public schools and the private school in their geometric thinking levels $t(103)=0.926, p>0.05$.

\section{Discussion of results}

The study was meant to investigate the Van Hiele Geometric thinking levels of form three students of 105 Junior High School students of Atebubu-Amantin in the Brong Ahafo Region of Ghana. It is clear from the descriptive analysis of the overall performance of the 105 JHS students that the lowest score was 0 , highest score was 11 . and a modal score of 7 was recorded. The mean score is 5.97 and the standard deviation is 1.988 . The correct response average rate for the various VHGT levels are $64.8 \%$ for questions $1-5,32.6 \%$ for questions $6-10,20.4 \%$ for questions $11-15$, for levels 1,2 , and 3 respectively. Also, the overall correct response rate for the entire 15 items is $39.27 \%$.

For the level's analyses, 84 (79.0\%), of the JHSs obtained less than half of the total score of 159 $(8.57 \%)$ of the JHSs obtained marks above half of the total score and, $12(11.43 \%)$ JHSs obtained exactly half the total. It revealed from the results of the VHGT that $65(61.19 \%)$ reached Van Hiele level 1 which is the visualization stage where geometric figures are identified based on their appearance. Level 2 of the VHGTT tested the ability of JHSs to analyze figures geometrically and only $17(16.19 \%)$ reached this level. Apart from that only $1(0.95 \%)$ reached level $3.22(20.95 \%)$ reached No level in the VHGT.

This is disturbing because the performance of JHS form three could have perform better. These findings are in line with previous studies by (Anas, 2018; Halat and Sahin, 2008; Pandisco and knight, 2010; Ndlove, 2014; and Armah, et al, 2017). The findings also reveal that a little above half of JHS students in Atebubu Amantin Municipal were found to be operating at van Hiela level 2. Also, only one was at level 3. which is consistent with other studies by (Anas, 2018; Armah, et al, 2017; Halat, 2008; Erdogan and Durmus, 2009; Halat and Sahin, 2008; Pandisco and Knight 2010) who also recorded very low performance in van Hiele levels 3,4 and 5 . If van Hiela level 3 is the pre-requisite for students leaving JHS and majority of form 3 students are below this level, then there is the need for an intervention about teaching geometry at the JHS. Basic school teachers need to be at level 3 and above if they should function well at the basic school (Crowley, 1987; Usiskin, 1982; and Armah, et al, 2017). This is to suggest that the students could easily visualize 
Van Hiele Geometric Thinking Levels of Junior High School Students of Atebubu Municipality in Ghana

B. Amidu and J. Nyarko

and identify properties of plane shapes which is for only level one and two. The JHS students also lacked the knowledge to create meaningful definitions and give informal arguments to justify their reasoning. These findings are in line with Baffoe and Mereku (2010) and Armah, et al (2017) who observed that Van Hiele level 3 is most difficult for learners because class inclusion such as square being types of rectangles was not understood by many teachers in the basic schools in Ghana. Only a few in service teachers understood geometry reasoning at level 4 of the VGHT. It is discovered from this study that geometry teaching is essentially focused on level 1 and 2 and very little or no emphasis on the advance levels 3,4 and 5.

\section{Conclusion}

For the geometric thinking levels of the VHGT, 22 (20.95\%) of the JHS students did not reach any of the levels. Also, 65 (61.9\%), 17(16.19\%), reached levels 1 and 2, respectively. The analysis revealed that the minimum score was 0 , maximum 11, and a mode 7 The mean and standard deviation of the JHS students score are 5.97 and 1.988 respectively. The correct response rate for level 0 was $20.95 \%$, level 1 was $61.91 \%$, level 2 was $16.19 \%$, and level 3 was $0.95 \%$. It can be claimed that, JHS students have not been taken through the appropriate method with the requisite skills to enable them grasp the necessary concept at this level

\section{Recommendations}

From the findings of this study, it is recommended that; Geometric thinking Levels of PTs should be determined and instructions should be applied based upon these Levels. In view of this, Basic school teachers should revise their instructional methods to utilize the VHPI in planning and delivering lessons. This would address the finding that teaching approaches adopted in the teaching of two-dimensional figures in their classrooms. Basic school teachers should be encouraged to use teaching learning materials in enhancing and developing the spatial orientation of JHS students. This suggestion was made in view of the finding that there was lack of effective use of teaching learning materials by JHS teachers in teaching two-dimensional figures.

\section{References}

Anamuah-Mensah, J. \& Mereku, D. K. (2005). Ghanaian Junior Secondary School two students abysmal Mathematics Achievement in TIMSS 2003: A consequence of the Basic School Mathematics. Mathematics Connection, 5(1), 1-11.

Anamuah-Mensah, J., Mereku, D. K., \& Asabere-Ameyaw, A. (2008). Ghanaian Junior Secondary School Students' Achievement in Mathematics and Science: Results from Ghana's participation in the 2007 Trends in International Mathematics and Science Study. Accra: Ministry EducationYouth and Sports.

Armah, R.B., Cofie,P.O., \& Okpoti , C. A. (2017). The Geometric Thinking Levels of Pre-service Teachers in Ghana. Higher Education Research. Vol. 2, No. 3, pp. 98-106. doi: 10.11648/j.her.20170203.14

Asante, J. N. \& Mereku, D. K. (2012). The Effect of Ghanaian Pre-service Teachers' Content Knowledge on their Mathematical Knowledge for teaching Basic School Mathematics. African Journal of Educational Studies in Mathematics and Sciences, 10, 23-37.

Asemani, E., Asiedu-Addo, S.K. \& Oppong, R.A. (2017). The Geometric Thinking Level of Senior High School students in Ghana. International Journal of Mathematics and Statistics Studies 5(3),pp.1-8. 
African Journal of Educational Studies in Mathematics and Sciences Vol. 15, 2019

Atebe, H. U. (2008). Students' Van Hiele levels of Geometric Thought and Conception in Plane Geometry: A collective case study of Nigeria and South Africa. Unpublished (Ph.D)Thesis.

Baffoe, E. \& Mereku, D. K. (2010). The van Hiele Levels of understanding of students entering Senior High School in Ghana. African Journal of Educational Studies in Mathematics and Sciences, 8, 51-61.

Crowley, M. L. (1987). The van Hiele Model of development of geometric thought. In M. M. Lindquist, \& A. P. Shulte (Eds.), Learning and teaching geometry, K-12, 1987 Yearbook (pp. 1-16). Reston, VA: National Council of Teachers of Mathematics.

Duru, A. (2010). The experimental teaching in some of topics geometry. Educational Research and Review. 5 (10): 584-592

Gutierrez, A., Jaime, A., \& Fortuny, J. M. (1991) An alternative paradigm to evaluate the acquisition of the van Hiele levels. Journal for Research in Mathematics Education, $22,237-251$.

Halat, E. \& Şahin, O. (2008). Van Hiele Levels of Pre- and In-Service Turkish Elementary School Teachers and Gender Related Differences in Geometry. The Mathematics Educator, 11(1/2), 143-158.

Halat, E. (2008). In-Service Middle and High School Mathematics Teachers: Geometric Reasoning Stages and Gender. The Mathematics Educator, 18(1), 8-14.

Mason, M. (1998). The van Hiele Levels of geometric understanding. In L. McDougal (Ed.). The professional handbook for teachers: Geometry (pp. 4-8). Boston: McDougalLittel1/Houghton-Mifflin.

Mullis, I. V. S., Martin, M. O., Foy, P., \& Arora, A. (2012). TIMMSE 2011 international results in mathematics. Chestnut Hill, MA: TIMSS\& PIRLS international study centre, Boston College.

National Council of Teachers of Mathematics (NCTM). (2009). Guiding Principles for Mathematics Curriculum and Assessment. Retrieved February, 2, 2014 from http://www.nctm.org/uploadedFiles/Math_Standards/NCTM\%20Guiding\%20Principles \%206 209.pdf

Siew, N.M., Chong, C.L., \& Abdullah, M.R. (2013). Facilitating students' Geometric Thinking through Van Hiele's Phase-Based learning using Tangram. Journal of Social Sciences. 9(3),pp. 101-111. doi: 10.3844/jssp.2013.101.111

Usiskin, Z. (1982). Van Hiele Levels and achievement in secondary school geometry: Cognitive development and achievement in secondary school geometry project. Chicago: of Chicago Press.

Van Hiele, P. M. (1957). The Problem of Insight, in Connection with School-children's Insight into the Subject Matter of Geometry. Doctoral dissertation, University of Utrecht.

Van Hiele, P. M. (1986). Structure and insight: A theory of mathematics education. Orlando:Academic Press.

Van Hiele, P. M. (1999). Developing Geometric Thinking through Activities that Begin with Play. Teaching Children Mathematics. 6: 310-316. 
Van Hiele Geometric Thinking Levels of Junior High School Students of Atebubu Municipality in Ghana

B. Amidu and J. Nyarko

Vojkuvkova, I. (2012). The van Hiele Model of Geometric Thinking. WDS'12 Proceedings of Contributed Papers. 1: 72-75. 